\title{
Erratum to: Reliability and Validity of the Arabic Version of the SF-36 Health Survey Questionnaire in Population of Khat Chewers-Jazan Region-Kingdom of Saudi Arabia
}

\author{
Kamaludin Ahmed Sheikh • Umar Yagoub • \\ Maged El-Setouhy • Rashad Alsanosy • \\ Sakhaudin Ahmed Mohamud
}

Published online: 28 December 2013

(C) Springer Science+Business Media Dordrecht and The International Society for Quality-of-Life Studies (ISQOLS) 2013

\section{Erratum to: Applied Research Quality Life (2013) DOI 10.1007/s11482-013-9291-1}

The names of third and fourth authors were misspelled. The correct names should be Maged El-Setouhy and Rashad Alsanosy as presented here.

The online version of the original article can be found at http://dx.doi.org/10.1007/s11482-013-9291-1.

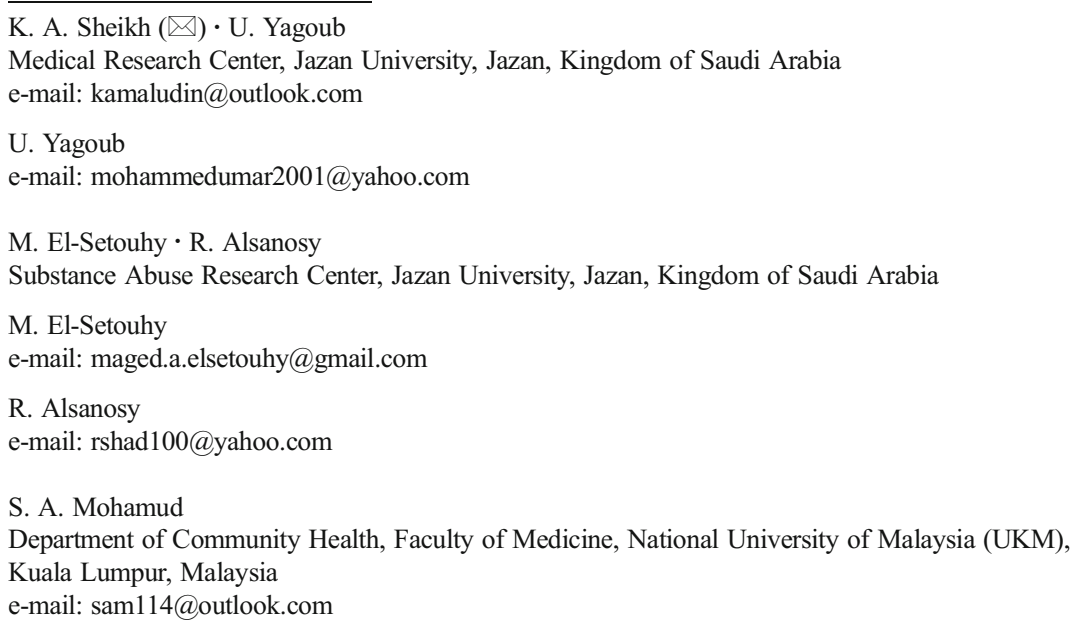

